Original Article

\title{
The effects of a reciprocal hip exercise on trunk flexion angle and sit-to-stand time in participants with flat backs
}

\author{
WON-GYU Yoo ${ }^{1)}$ \\ 1) Department of Physical Therapy, College of Biomedical Science and Engineering, Inje University: \\ 607 Obangdong, Gimhae, Gyeongsangnam-do 621-749, Republic of Korea
}

\begin{abstract}
Purpose] This study developed a reciprocal hip exercise using Thera-Band for those with flat lumbar spines and observed changes in standing and movement angles during sit-to-stand. [Participants and Methods] Eleven females participated in this study. The participants performed the reciprocal hip exercise using Thera-Band. [Results] The trunk flexion angle increased significantly after reciprocal hip exercise. The sit-to-stand time after reciprocal hip exercise was significantly faster than that before exercise. [Conclusion] The reciprocal hip exercise would useful for patients with flat back who can then sit and work for long periods.

Key words: Flat back, Hip exercise, Sit-to-stand
\end{abstract}

(This article was submitted Mar. 8, 2018, and was accepted May 7, 2018)

\section{INTRODUCTION}

Prolonged computer work requires that the upper body remain static ${ }^{1)}$. When bending to view the screen, the head and spine experience stress, which creates spinal muscle imbalance, concentrating stress on the surrounding tissues and joints and causing pain and musculoskeletal strain ${ }^{2}$. In particular, sitting with the trunk inclined forward causes abnormal bending, placing about three times the normal load on the cervical vertebrae, creating an abnormal spinal curve ${ }^{3)}$. The joints in the lower part of the spine are fixed at the sacroiliac joints. Thus, a continuously bent lumbar spine induces lordosis ${ }^{3,4)}$. Assuming a flat-back position reduces stress on the discs at the waist and increases the external forces pulling the pelvis rearward, resulting in reduction of spinal extensor and hip activity and increasing lumbar spine instability and the muscular demands on the lower trunk ${ }^{4}$. Thera-Band is a well-regarded strength training tool that is inexpensive, small, and versatile ${ }^{5)}$. Therefore, this study developed a reciprocal hip exercise using Thera-Band for those with flat back and observed changes in standing and movement angles during sit-to-stand.

\section{PARTICIPANTS AND METHODS}

Eleven females with flat back, aged $22.0 \pm 1.2$ years whose body mass and height were $55.4 \pm 6.2 \mathrm{~kg}$ and $162.0 \pm 5.4 \mathrm{~cm}$, participated in this study. Using the dual inclinometer, it is defined as a patient if the angles T1 to T12 and L1 to L5 are both below 20 degrees. The study purpose and the methods were explained to all participants, who provided written informed consent as defined by the Declaration of Helsinki before participating. This study developed a reciprocal hip exercise that could be easily practiced by those with flat lumbar spines while sitting. First, with the knee angle set at $90^{\circ}$, the middle of a $150 \times 15 \times 0.5-\mathrm{cm}$ elastic band was passed below both foots, and the two ends of the band were tied on both thighs. Then, the hip was flexed with the other foot pressing the band on ground to provide resistance. The participants were performed the seven sets reciprocal hip flexion for $30 \mathrm{~min} /$ day during 15 days. A video motion analyzer was used to measure angles and 
the sit-to-stand time. The trunk flexion angle was calculated as the angle between the line from the acromion to the greater trochanter and the line from the greater trochanter to the knee joint. Sit-to-stand times were measured from the point when the thighs left the chair to the point when the knees were completely straightened. Trunk flexion angles were recorded using a digital camera, and video motion analysis software (Pro-Trainer 10.1; Sports Motion, Cardiff, CA, USA) was used to analyze kinematic data. The SPSS statistical package (ver. 14.0; SPSS, Chicago, IL, USA) was used to compare the trunk flexion angles and sit-to-stand times. Statistical significance was evaluated using the paired t-test, and the level of significance was set at $\mathrm{p}<0.05$.

\section{RESULTS}

The trunk flexion angle increased significantly after reciprocal hip exercise $\left(81.6 \pm 8.83\right.$ vs. $\left.75.9 \pm 5.02^{\circ}\right)(\mathrm{p}<0.05)$. The sit-to-stand time after reciprocal hip exercise $(1.40 \pm 0.26 \mathrm{sec})$ was significantly faster than that before exercise $(1.85 \pm 0.44$ $\sec )(\mathrm{p}<0.05)$.

\section{DISCUSSION}

This study result showed that the trunk flexion angles averaged $75.9^{\circ}$ before and $81.6^{\circ}$ after the reciprocal hip exercise, indicating strengthening of the hip flexor and erector spinae muscles, the muscles responsible for pelvic tilt. During the sit-to-stand motion, an increase in the trunk flexion angle indicated improvement in dynamic balance, which was attributable to enhanced stability ${ }^{2,3)}$. Sit-to-stand motion requires pronounced forward curvature of the body, and after such action, many muscles simultaneously contract to allow standing under conditions where intermediate bodily regions are unstable. The reciprocal hip exercise would requires that agonist and antagonist muscles are contracted reciprocally ${ }^{5}$. Indeed, reciprocal hip exercise may facilitate phasic, coordinated muscle activity ${ }^{5)}$. Here, the reciprocal hip exercise not only increased flexion of the targeted hip but also strengthened the other leg, enhancing trunk stability in response to apparently unstable conditions according to single leg support. The sit-to-stand time was decreased. The reciprocal hip exercise can be easily performed by individuals with flat backs even while sitting, increasing the strengthening of the lower extremity muscles, and improving trunk stability. Therefore, the reciprocal hip exercise is thus useful for patients with flat lumbar backs who can then sit and work for long periods without pain.

\section{Funding}

This research was supported by Basic Science Research Program through the National Research Foundation of Korea (NRF) funded by the Ministry of Education (No. 2017R1D1A1B03035485).

\section{Conflict of interest}

None.

\section{REFERENCES}

1) Yoo WG, Park SY: Effects of posture-related auditory cueing (PAC) program on muscles activities and kinematics of the neck and trunk during computer work Work, 2015, 50: 187-191. [Medline]

2) Sahrmann SA: Diagnosis and treatment of movement impairment syndromes. St. Louis: Mosby, 2002.

3) Kendall FP, McCreary EK, Provance PG, et al.: Muscles: testing and function with posture and pain, 5th ed. Baltimore: Williams \& Wilkins, 2005.

4) Kim KT, Lee SH, Huh DS, et al.: Restoration of lumbar lordosis in flat back deformity: optimal degree of correction. Asian Spine J, 2015, 9: 352-360. [Medline] [CrossRef]

5) Fujiwara T, Liu M, Tanuma A, et al.: Pedalling exercise for neuromuscular re-education: a review. Crit Rev Phys Rehabil Med, 2005, 17: 163-178. [CrossRef] 